\title{
PKM Peningkatan Daya Saing Produk Dengan Menerapkan Strategi Marketing Mix dan Teknologi Pada Kelompok Usaha Gula Semut di Desa Pernasidi
}

\author{
Rizki Wahyudi ${ }^{1}$ \\ Universitas Amikom Purwokerto, rizki.key@gmail.com \\ Muliasari Pinilih ${ }^{2}$ \\ Universitas Amikom Purwokerto, mpinilih@amikompurwokerto.ac.id \\ Luzy Oktaviany ${ }^{3}$ \\ Universitas Amikom Purwokerto, luzy@amikompurwokerto.ac.id ${ }^{3}$
}

\begin{abstract}
Abstrak
UD. Kali Mengaji merupakan usaha dagang yang bergerak di bidang produksi gula semut di Pernasidi. UD. Kali Mengaji bekerja sama dengan petani dan pengepul gula sebagai pemasok produk gula. Gula yang diproduksi oleh UD. Kali Mengaji harus memenuhi standar kebersihan dan higienis. Namun, selama proses pengolahannya petani terkadang tidak memperhatikan faktor tersebut. Padahal salah satu aspek yang akan dilihat konsumen dalam membeli suatu produk adalah faktor kebersihan atau higienis. Permasalahan lain yang muncul adalah belum adanya branding produk gula tersebut. Selama ini, UD Kali Mengaji masih menjual tanpa menggunakan brand atau merk. Aspek terakhir yang menjadi permasalahan adalah pemasaran produk. Pemasaran produk ini masih menggunakan bantuan pihak ketiga dan belum melakukan pemasaran secara mandiri. Hal ini mengakibatkan nilai jual produk gula semut cukup rendah. Secara garis besar, permasalahan mitra ini terfokus pada belum pahamnya mitra terhadap bauran pemasaran atau marketing mix. Solusi untuk mengatasi permasalahan ini dengan memberikan penyuluhan, pendampingan dan pelatihan terhadap mitra. Untuk permasalahan kebersihan akan dilakukan dengan memberikan penyuluhan dan pendampingan kepada petani mengenai dapur bersih dalam proses produksi. Penyuluhan ini diharapkan akan meningkatkan kesadaran petani dalam menjaga aspek kebersihan dalam proses produksi. Solusi belum terdapatnya branding produk gula semut akan diatasi dengan memberikan workshop mengenai branding dan packaging produk Sementara, pemasaran yang belum mandiri akan diatasi dengan memberikan pelatihan dan pendampingan workshop Internet Marketing dan pembuatan web dalam proses pemasaran produk. Dalam hal ini menyelesaikan permasalahan mitra dengan menerapkan model marketing mix yang berfokus pada product dan promotion, hasil dari kegiatan pertama mitra petani mendapatkan pengetahuan terkait terkait dapur bersih dan pembuatan dapur bersih, kegiatan ke dua memberikan pelatihan branding dan packaging produk mitra telah dibuatkan branding produk dan packaging produk sendiri, untuk kegiatan ketiga adalah pembuatan website untuk sarana penjualan mandiri, yang dapat diakses melalui url: udkalimengaji.com. Disamping itu Tungku efesien energi yang di buat dapat mengehemat bahan bakar sampai 30\%-40\% dan Sealer yang diserahkan kepada mitra dari yang lama mengepres butuh waktu kurang 1 menit sementara sealer baru bisa mengepres di bawah 30 detik Pesanan 1 ton $=100$ bag, pakai satu sealer yang lama waktu 3 jam Sekarang untuk dua sealer bisa diselesai dalam 1,5 jam.
\end{abstract}

Kata Kunci: Gula Semut, Marketing Mix, Internet Marketing, Pernasidi 


\begin{abstract}
Abstrak
UD. Kali Mengaji is a trading business which is engaged in the production of ant sugar in Pernasidi. UD. Kali Mengaji cooperates with farmers and sugar collectors as suppliers of sugar products. Sugar produced by UD. Kali Mengaji must meet hygiene and hygiene standards. However, during the processing process farmers sometimes do not pay attention to these factors whereas one aspect that consumers will see in buying a product is hygiene or hygiene factors. Another problem that arises is the absence of branding sugar products. During this time, UD Kali Mengaji still sells without using a brand or brand. The last aspect that becomes a problem is product marketing. This product marketing still uses the help of third parties and has not done marketing independently. This results in the selling value of ant sugar products are quite low. Broadly speaking, this partner's problem is focused on the partners' lack of understanding of the marketing mix or marketing mix. The solution to overcome this problem is by providing counselling, assistance and training to partners. For hygiene problems, it will be done by providing counselling and assistance to farmers regarding clean kitchens in the production process. This counselling is expected to increase farmer awareness in maintaining hygiene aspects in the production process. The solution to the absence of ant sugar product branding will be overcome by providing workshops on product branding and packaging. Meanwhile, marketing that is not yet independent will be overcome by providing training and mentoring on Internet Marketing workshops and web creation in the product marketing process. In this case, solving partners' problems by implementing a marketing mix model that focuses on product and promotion, the results of the first activity of the farmer partners get knowledge related to clean kitchens and making clean kitchens, the second activity is providing branding and product packaging partners have made branding products and own product packaging, for the third activity is the creation of a website for independent sales facilities, which can be accessed via URL: udkalimengaji.com. Besides that, the energy efficiency stove can save up to $30 \%-40 \%$ and sealers delivered to partners from the old press need less than 1 minute while the new sealer can press under 30 seconds. Order 1 ton $=100$ bags, use one sealer that lasts 3 hours Now for two sealers, it can be finished in 1.5 hours.
\end{abstract}

Keywords: Ant Sugar, Marketing Mix, Internet Marketing, Pernasidi

\title{
Pendahuluan
}

Pernasidi adalah desa yang terletak di Kecamatan Cilongok Kabupaten Banyumas. Desa ini terletak jauh dari hiruk pikuk perkotaan. Sebagian besar warga masyarakat mempunyai lahan sendiri, disamping mempunyai kebun Desa yang disebut Desa Gula. Desa ini dinamakan Desa Gula karena sebagian besar warganya memiliki pohon kelapa. Pohon kelapa tersebut memberikan penghidupan untuk mencukupi kehidupan sehari-hari mereka. Sumber penghidupan karena dari pohon kelapa dapat diambil nira kelapa. Nira kelapa adalah sari dari air kelapa yang ditaruh di pohon kelapa menggunakan bambu atau semacamnya untuk mengumpulkan sari nira kelapa selama 2-3 hari dan hasilnya diproses menjadi gula.

Gula yang dihasilkan dari desa ini sangat unik yaitu gula ini bukan berbentuk kotak, bundar seperti labilnya gula yang terdapat dipasar. Gula ini diproses oleh warga masyarakat (Penderes) sebutan dari orang yang mempunyai pohon kelapa yang mengambil nira kelapa pada pohon kelapa. Gambar 1. Pohon kelapa yang terdapat di kebun warga. 


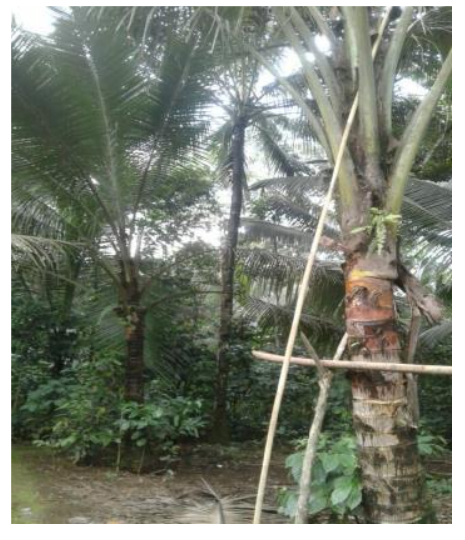

Gambar 1. Pohon Kelapa yang Terdapat di Kebun Warga

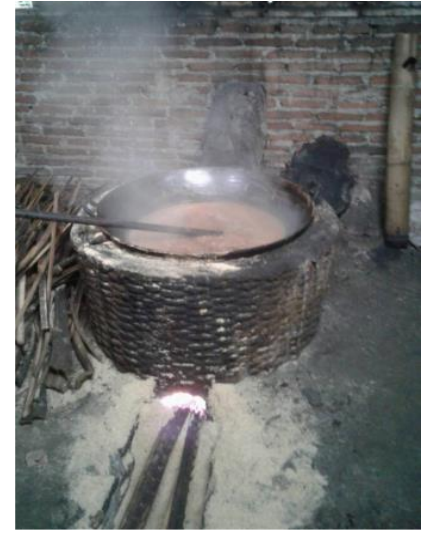

Gambar 2. Proses Perebusan Nira Kelapa menjagi Gula.

Penderes melakukan proses perebusan terhadap nira kelapa di wajan besar dengan api harus selalu menyala agar proses rebusan nira kelapa dapat menjadi gula yang dapat diproses menjadi gula yang tidak biasanya berikut proses perebusan nira kelapa menjadi gula.

Setelah proses perebusan nira kelapa selesai, maka hasilnya dituangkan ke dalam wajan atau tempat untuk mendinginkan nira kelapa yang masih panas agar dingin selama 3 jam. Sebelum dingin gula yang sudah mulai mengeras mulai dilakukan penggilingan agar gula menjadi remuk, setelah remuk gula tersebut diayak untuk mendapatkan gula yang bersih dan terhindar dari hewan kecil yang tidak terlihat. Gambar 3 gula yang sudah diremuk menjadi serbuk basah.

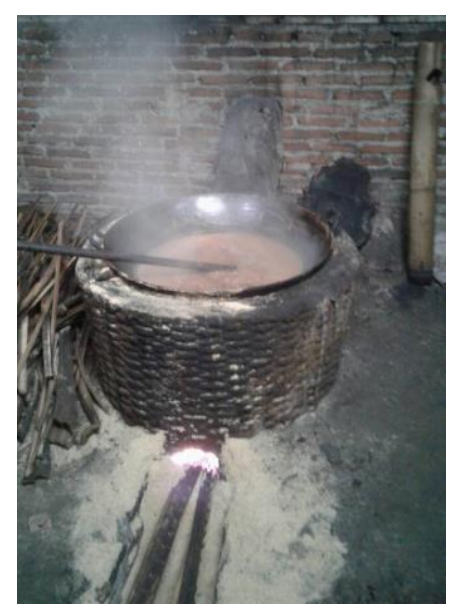

Gambar 3. Gula yang Sudah Diremuk menjadi Serbuk Basah

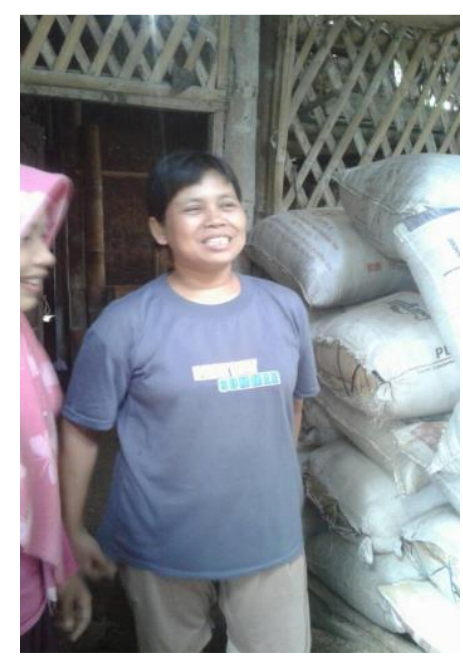

Gambar 4. Petani Gula Serbuk

Setelah menjadi gula serbuk, selanjutnya adalah "petani" sebutan warga yang sudah menjadikan nira kelapa menjadi Gula Serbuk Basah. Petani ini akan memberitahukan 
kepada pengepul agar gula hasilnya segera diambil/diangkut utnuk proses selanjutnya. Terdapat 4 Aktor/Mitra yang saling berhubungan dalam proses pengepakan Gula Serbuk ini agar menjadi gula yang bersaing di pasar internasional.

\section{Mitra Penderes/ petani}

Petani adalah orang/warga yang bertugas mejadikan nira kelapa menjadi serbuk gula basah, yang akan di distribusikan ke pengepul, dalam hal ini pengepul disetiap desa mempunyai 1-2 orang, tergantung dari banyaknya warga di desa tersebut.

Petani yang dikelola oleh UD Kali Mengaji mendapatkan Sertifikat HACCP (Hazard Analysis and Critical Control Points) sebagai standarisai bahwa pohon kelapa yang ada di kebun petani tidak memakai bahan-bahan kimia. Sertifikat ini pula sebagai syarat yang menitikberatkan pada analisa bahaya makanan, sebagai standarisasi pengolahan makanan yang sehat bertaraf internasional.

Alat-alat yang digunakan untuk menunjang standarisasi produksi yaitu:
a. Wajan aluminuim
b. Pongkor plastik
c. Ayakan stenlis
d. Tempurung kelapa.

Petani yang dibina untuk menghasilkan Gula Serbuk Basah yaitu pada petani di 6 Desa, 4 Kecamatan antara lain :
a. Desa Jingkang Kec. Ajibarang
b. Desa Pejogol Kec. Cilongok
c. Desa Taman Sari Kec. Karang lewas
d. Desa Langgosari Kec. Cilongok
e. Desa Cilongok Kec. Cilongok
f. Desa Karang Kemiri Kec. Pekuncen

Jumlah petani yang tergabung dalam kemitraan UD Kali Mengaji adalah 520 petani, rata-rata petani mempunyai 50 pohon kelapa yang menghasilkan 5 sampai $10 \mathrm{~kg}$ perhari/petani. Gambar 4. Petani Gula Serbuk

\section{UD Kali Mengaji}

UD Kali Mengaji didirikan tanggal 2 April 2010 yang berawal dari membina beberapa orang penderes di Desa Tamansari Kec. Karanglewas Kab. Banyumas. Pembinaan tersebut meliputi sosisalisasi pembuatan gula kristal, pembuatan dapur lembaga sertifikasi internasional CU (Control Union) yang berkantor di Jakarta. Kemudian setelah melakukan beberapa pembinaan pada petani/penderes maka mulailah UD Kali Mengaji mendapat kepercayaan dari pasar. Mula mula UD Kali Mengaji mendapatkan pesanan barang dari JCO (Java Choice of Organics) sebanyak 1 ton pada tanggal 22 November 2013, kemudian meningkat menjadi 2 ton pada tanggal 10 September 2014 dan sekarang sudah mendapat pesanan yang rutin perbulannya sebanyak 30 ton. Oleh karena itu pasar yang semakin banyak maka UD Kali Mengaji membuat dapur bersih di 6 desa 4 kecamatan, dan membagikan alat-alat tempur 
kepada petani/penderes. Untuk memproduksi sumber pangan yang higienis UD kali mengaji melakukan pengendalian bahaya pengan dengan menggunakan Sistem HACCP yakni :

a. Mengidentifikasi setiap tahapan dalam kegiatan operasional yang kritis untuk keamanan pangan

b. Menerapkan prosedur pengendalian secara efektif pada tahap kegiatan operasional tersebut.

c. Meninjau prosedur pengendalian secara berkal dan setiap kali dilakukan perubahan kegiatan operasional.

Permasalahan yang ada adalah Gula yang dipasarkan oleh UD. Kali Mengaji harus memenuhi standar kebersihan dan higienis. Namun, dilapangan selama proses pengolahannya petani terkadang masih ada yang tidak memperhatikan faktor tersebut dalam proses produksi. Padahal salah satu aspek yang akan dilihat konsumen dalam membeli suatu produk adalah faktor kebersihan atau higienis. Menurut (Purnomo, D., Mukti, G.W., Dan Hendriani, 2013) dan (Purnomo, D., Mukti, G.W., Dan Hendriani, 2013) dan (Surjono, 2017) untuk standar dapur bersih gula semut adalah lantai tidak tanah, ada pembuangan asap pembakaran bahan bakar sehingga tidak masuk ke wajan, tersedianya air bersih seperti kran air.

permasalahan yang muncul adalah belum adanya branding produk gula tersebut. Selama ini, UD Kali Mengaji masih menjual tanpa menggunakan brand atau merk. Pada penelitian (Diarta, Lestari, \& Dewi, 2016) dan menjelaskan merk dan kemasan merupakan hal penting dalam meningkatkan citra produk. Aspek terakhir yang menjadi permasalahan adalah pemasaran produk. Pemasaran produk ini masih menggunakan bantuan pihak ketiga dan belum melakukan pemasaran secara mandiri. Hal ini mengakibatkan nilai jual produk gula semut cukup rendah. Secara garis besar, permasalahan mitra ini terfokus pada belum pahamnya mitra terhadap bauran pemasaran atau marketing mix. Solusi untuk mengatasi permasalahan ini dengan memberikan penyuluhan, pendampingan dan pelatihan terhadap mitra. Untuk permasalahan kebersihan akan dilakukan dengan memberikan penyuluhan dan pendampingan kepada petani mengenai dapur bersih dalam proses produksi. Penyuluhan ini diharapkan akan meningkatkan kesadaran petani dalam menjaga aspek kebersihan dalam proses produksi. Solusi belum terdapatnya branding produk gula semut akan diatasi dengan memberikan workshop mengenai branding dan packaging produk Sementara, pemasaran yang belum mandiri akan diatasi dengan memberikan pelatihan dan pendampingan workshop Internet Marketing dan pembuatan web dalam proses pemasaran produk. Menurut (Maya Demishkevich, 2015), (Purwana, Rahmi, \& Aditya, 2017) dan (Catur Yuantari, Kurniadi, \& Kesehatan, 2016) dengan memanfaatkan digital marketing dapat membantu meningkatkan citra perusahaan dan memperluas pasar diantaranya yang bisa diterapkan adalah Website dan media sosial. 


\section{Metode}

Pelaksanaan PKM ini akan dilakukan oleh Tim Pelaksana dengan tahapan sebagai berikut:

1. Melakukan koordinasi internal dengan Mitra di Desa Pernasidi Kecamatan Cilongok Kabupaten banyumas.

2. Terjun langsung kelapangan memantau kebun, petani/penderes, pengepul dan pihak dari UD Kali Mengaji Desa Pernasidi Kecamatan Cilongok Kabupaten banyumas.

3. Sosialisasi tentang solusi yang ditawarkan untuk mengatasi permasalahan di Mitra di Desa Pernasidi Kecamatan Cilongok Kabupaten Banyumas. Adapun solusi yang ditawarkan adalah :

a. Penyuluhan dan pendampingan kepada petani mengenai dapur bersih dalam proses produksi gula.

b. Workshop mengenai branding and packaging produk guna menambah identitas produk.

c. Workshop penggunaan sistem penetapan harga produk.

d. Workshop Internet Marketing dan pembuatan web untuk pemasaran produk.

4. Koordinasi dengan ketiga mitra yaitu Petani, Pengepul dan Kepala bagian UD Kali Mengaji untuk proses pelaksanaan kegiatan PKM. Mitra akan berkonstribusi dengan menyediakan tempat untuk pelatihan dan penyuluhan.

5. Pelaksanaan kegiatan PKM dengan mitra meliputi :

a. Penyuluhan dan pendampingan kepada petani mengenai dapur bersih dalam proses produksi gula.

b. Workshop mengenai branding and packaging produk guna menambah identitas produk.

c. Workshop penggunaan sistem penetapan harga produk.

d. Workshop Internet Marketing dan pembuatan web untuk pemasaran produk.

\section{Hasil dan Pembahasan}

Pelaksanaan pengabdian dimulai dengan melakukaan koordinasi dengan mitra baik UD Kali Mengaji maupun dengan petani. Permasalahan yang terjadi menjadi lebih komplek dalam menghadapi persaingan bisnis dalam gula semut. Beberapa kegiatan yang telah terlaksana untuk memperbaiki permasalahan di UD Kali Mengaji adalah:

\section{a. Dapur Bersih}

Pembuatan dapur bersih bagi petani dimaksudkan untuk menunjang kegiatan produksi gula semut. Awal pengerjaan kegiatan ini berupa sosialisasi perawatan pohon kelapa agar mampu menunjang kegiatan produksi gula kelapa. Kegiatan ini dengan mengundang Ir. Mujiono, MS. selaku pembicara utama dalam sosialisasi perawatan kelapa. Kegiatan ini dilakukan pada 20 Juli 2019 di KPRI KOGAT Cilongok. Kegiatan ini diikuti oleh petani yang merupakan mitra UD Kali Mengaji yang diikuti oleh sekitar 18 orang dan pelaksanaan sosialisasi selama dua jam. Pelaksanaan kegiatan ini dapat dilhat pada gambar berikut 


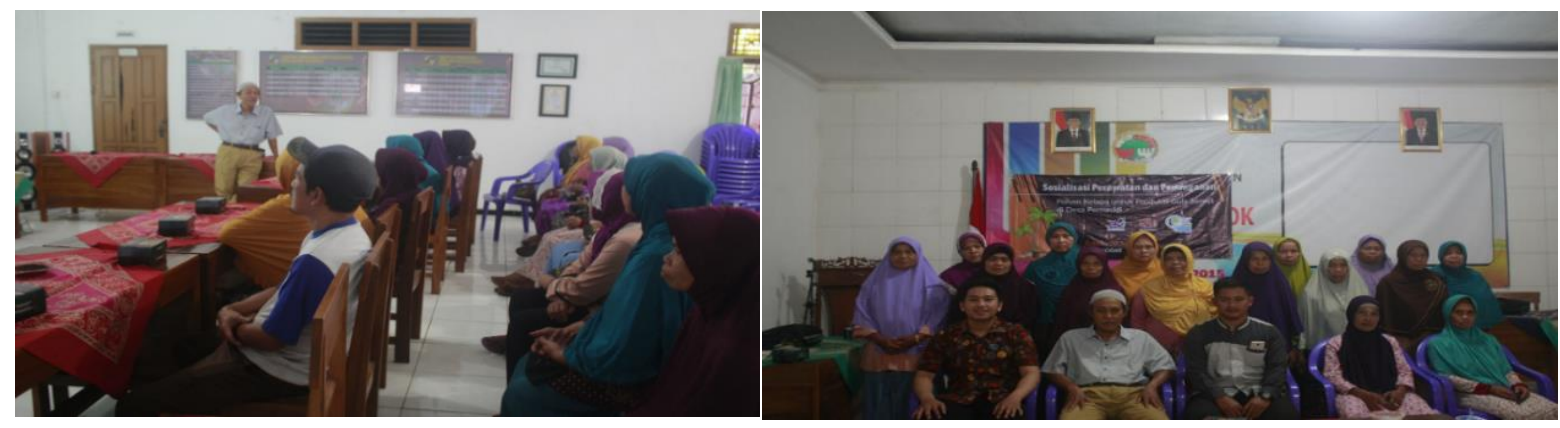

Gambar 5. Kegiatan Sosialisasi Perawatan Kelapa

Perawatan kelapa akan menjadi sia-sia jika tidak dibarengi dengan penerapan dapur bersih dalam mengolah produksi nira yang didapatkan. Nira tersebut kemudian dimasak dan untuk menghindari terjadinya pengawetan dengan bahan kimia maka wajib menggunakan laru alami seperti kulit manggis. Aspek lain yang pelu diperhatikan adalah dapur bersih. Salah satu bagian dari dapur bersih adalah pembuatan tungku efisien energi bagi petani. Pembuatan tungku efisiensi energi ini direncanakan akan diadakan untuk dua mitra, namun baru dilakukan pada satu mitra. Pembuatan tungku ini dilakukan pada 30 Juli 2019 di salah satu mitra yaitu petani di Desa Jingkang. Pembuatan tungku ini dilaksanakan selama 1 hari full. Setelah selesai pembuatan tungku efisiensi energi, tungku tersebut perlu didiamkan terlebih dahulu selama dua minggu sebelum digunakan dalam proses produksi. Setelah dua minggu, maka tungku akan dinyalakan dengan api kecil terlebih dahulu agar proses pemanasan dapat berhasil maksimal. Kegiatan pembuatan tungku ini akan terlihat pada Gambar 6.

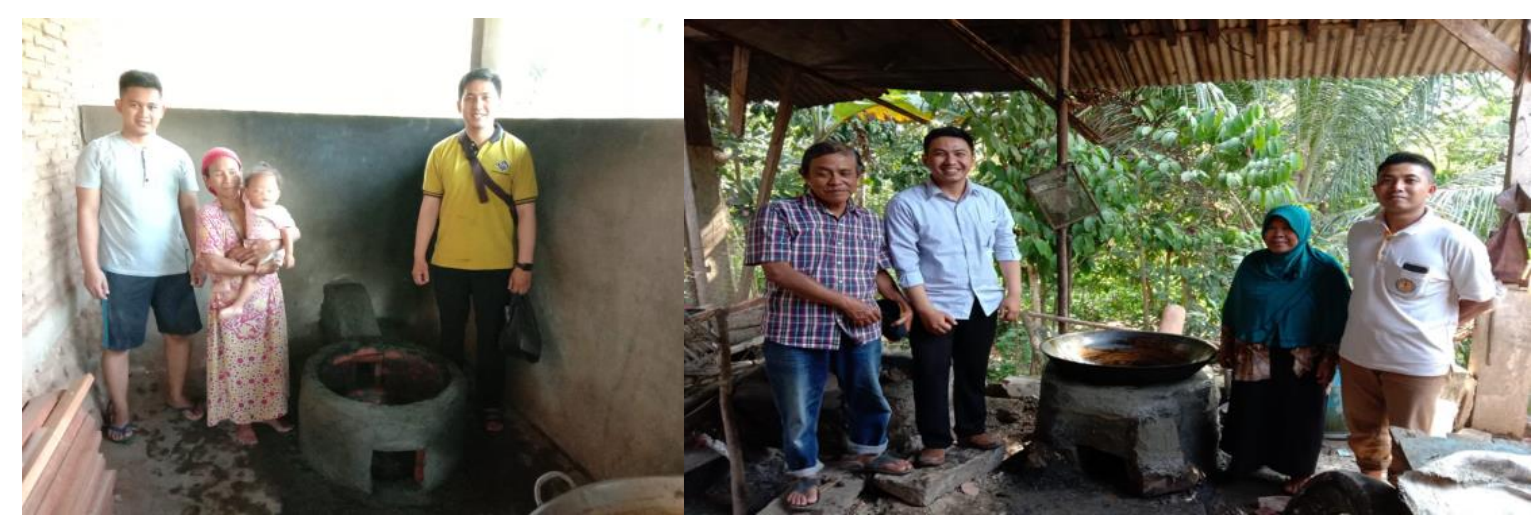

Gambar 6. Pembuatan Tungku Efisien Energi

Pembuatan tungku ini didesain supaya asap tidak masuk ke dalam ruangan sehingga produksi gula semut ini tetap terjaga higienisnya. Pembuatan dapur bersih kemudian akan dilanjutkan dengan memplester lantai dan membuat saluran air agar area produksi tetap akan higienis. Pembuatan dapur bersih ini akan membantu dalam menunjang produksi gula semut. Selain pembuatan tungku, pelaksana pengabdian 
juga membantu dengan memberikan wajan alumunium guna menunjang pembuatan gula semut untuk petani.

b. Internet Marketing

Permasalahan yang dihadapi oleh mitra terutama UD Kali Mengaji adalah belum banyaknya yang paham mengenai produk gula semut UD Kali Mengaji. Solusi yang ditawarkan adalah Internet Marketing. Internet Marketing ini akan memuat company profile dari UD Kali Mengaji sehingga dapat dikenal oleh masyarakat lokal dan luar negeri. Company profile ini memuat profil UD Kali Mengaji, produk-produk yang dihasilkan oleh UD Kali Mengaji, dan informasi mengenai UD Kali Mengaji seperti lokasi, contact person dan form pemesanan produk yang dihasilkan oleh UD Kali Mengaji. Pembuatan company profile ini masih dalam taraf pengembangan oleh tim developer. Website Internet Marketing dapat dilihat pada gambar 7.

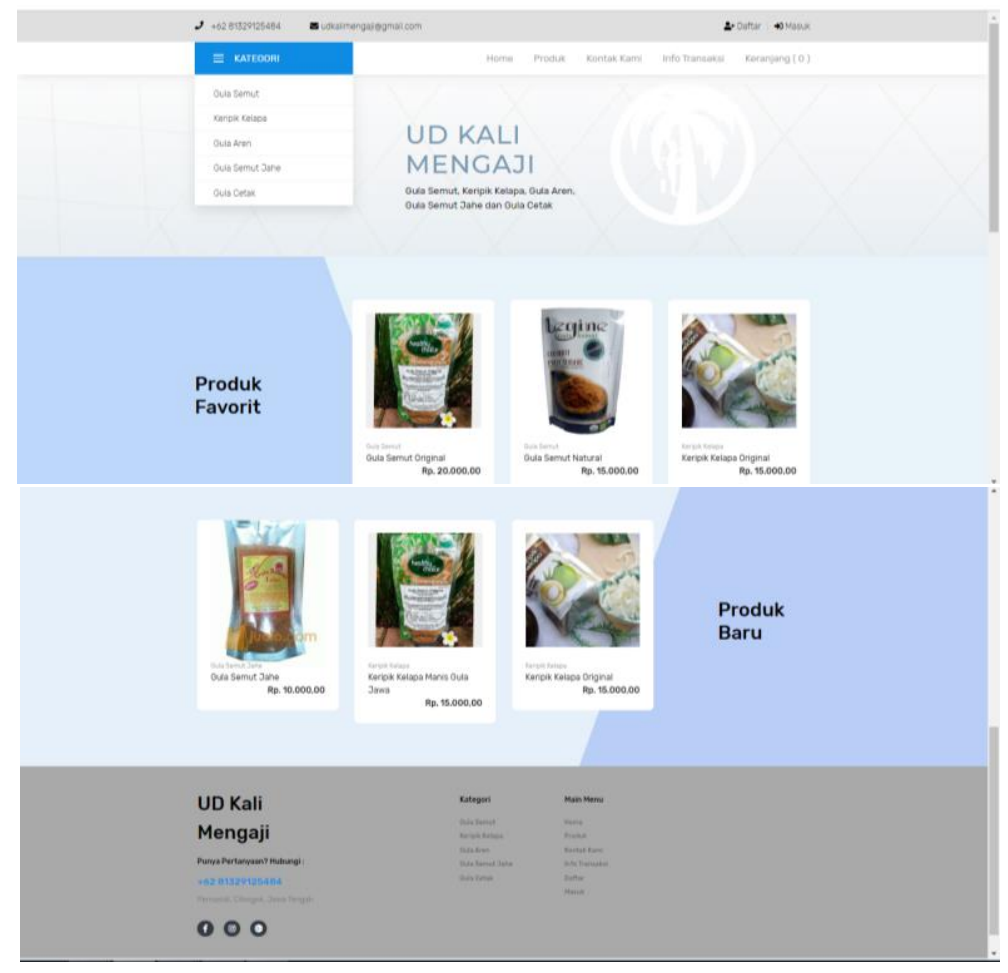

Gambar 7. Website UD. Kali Mengaji

Dalam menunjang pemasaran produk akan membantu dalam proses branding produk dan packaging produk. Branding dan packaging produk menjadi daya tarik pertama dalam proses marketing. Proses branding dan packaging dalam laporan kemajuan ini masih berupa desain awal dan belum merupakan desain final dikarenakan masih dalam proses pengembangan.

Pada awalnya UD Kali Mengaji sudah pernah mencoba memasarkan produk gula semut sendiri, namun mengalami kesulitan karena masalah utama belum terdapat mampu melakukan branding produk dan packaging dengan baik. Hal ini mengakibatkan proses pemasaran produk dari UD Kali Mengaji belum maksimal 
untuk pasar lokal. Permasalahan lainnya dalam proses pemasaran online ini adalah sertifikasi Halal yang dimiliki oleh UD Kali Mengaji sudah habis masa berlakunya. Maka untuk menunjang pemasaran dibutuhkan sertifikasi Halal dalam produk yang akan dipasarkan oleh UD Kali Mengaji. Untuk membantu perpanjangan sertifikasi Halal maka salah satu personel yaitu Ika Purwati mengikuti Pelatihan Sistem Jaminan Halal yang diadakan oleh Majelis Ulama Indonesia Provinsi Jawa Tengah yang dilaksanakan pada 6 Agustus 2019. Hasil pelatihan dapat dilihat pada sertifikat pada Gambar 8.

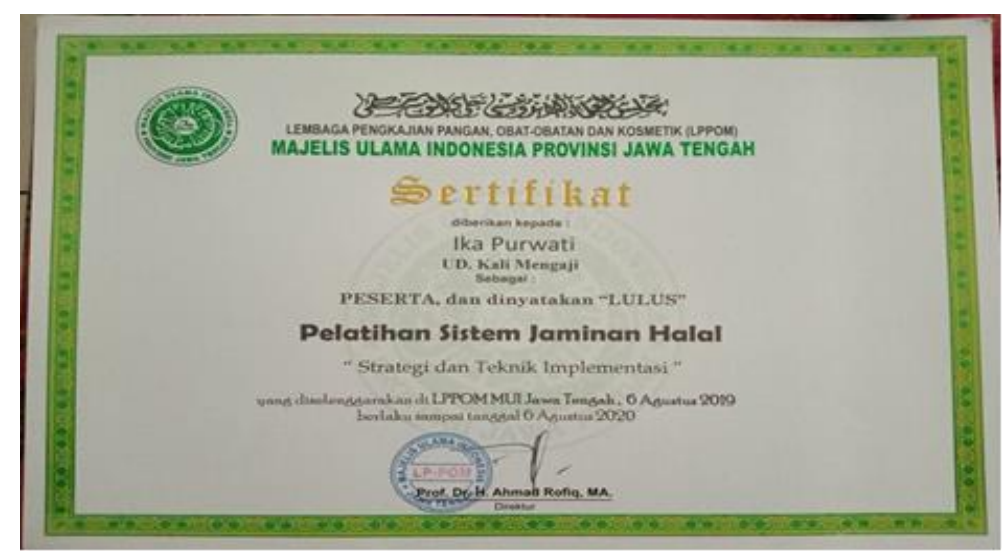

Gambar 8. Sertifikat Pelatihan Sistem Jaminan Halal

\section{Simpulan dan Rekomendasi}

\section{A. Simpulan.}

hasil dari kegiatan pertama mitra petani mendapatkan pengetahuan terkait terkait dapur bersih dan pembuatan dapur bersih, kegiatan ke dua memberikan pelatihan branding dan packaging produk mitra telah dibuatkan branding produk dan packaging produk sendiri, untuk kegiatan ketiga adalah pembuatan website untuk sarana penjualan mandiri, yang dapat diakses melalui url: udkalimengaji.com. Disamping itu Tungku efesien energi yang di buat dapat mengehemat bahan bakar sampai 30\%-40\% dan Sealer yang diserahkan kepada mitra dari yang lama mengepres butuh waktu kurang 1 menit sementara sealer baru bisa mengepres di bawah 30 detik Pesanan1 ton $=100$ bag, pakai satu sealer yang lama waktu 3 jam Sekarang untuk dua sealer bisa diselesai dalam 1,5 jam

\section{B. Saran}

Kegiatan pembuatan tungku efesien energi akan di tambah di beberapa mitra lainnya, Dapat dilakukan pengabdian lebih lanjut dengan materi yang lebih advance.

\section{Acknowledgements}

Penelitian dibiayai oleh Direktorat Riset dan Pengabdian dan Pengembangan Kementrian Riset, Teknologi dan Pendidikan Tinggi Pada Skim PKM (Pengabdian Kepada Masyarakat) Tahun 2019 berdasarkan Surat Kontrak nomor 004/L6/AK/SP2H/PPM/2019. 


\section{Daftar Pustaka}

Catur Yuantari, M., Kurniadi, A., \& Kesehatan, F. (2016). Pemanfaatan Teknologi Informasi Untuk Meningkatkan Pemasaran Hasil Pertanian Di Desa Curut Kecamatan Penawangan Kabupaten Grobogan Jawa Tengah. Techno.COM, 15(1), $43-47$.

Diarta, I. K. S., Lestari, P. W., \& Dewi, I. A. P. C. (2016). Strategi Branding dalam Promosi Penjualan Produk Pertanian Olahan PT . Hatten Bali untuk Pasar Pariwisata Indonesia. Jurnal Manajemen Agribisnis, 4(2), 170-187. Retrieved from https://ojs.unud.ac.id/index.php/agribisnis/article/download/27852/17540

Maya Demishkevich. (2015). Small Business Use of digital marketing: Findings from Case Studies. Walden University.

Purnomo, D., Mukti, G.W., Dan Hendriani, R. (2013). Workshop Dan Pendampingan Teknis Penerapan Standar Sanitasi Dan Malati Kecamatan Naringul Kabupaten Cianjur Workshop and Technical Assistance Application of Rural AgroIndustrial Sanitary and Hygiene Standards in Balegede and Malati Village, Naringul Ci, 2(1), 16-27.

Purwana, D., Rahmi, R., \& Aditya, S. (2017). Pemanfaatan Digital Marketing Bagi Usaha Mikro, Kecil, Dan Menengah (UMKM) Di Kelurahan Malaka Sari, Duren Sawit. Jurnal Pemberdayaan Masyarakat Madani (JPMM), 1(1), 1-17. https://doi.org/10.21009/jpmm.001.1.01

Surjono, G. (2017). Industri Rumah Tangga Gula Semut sebagai Wahana Peningkatan Kesejahteraan Sosial Keluarga, 151-172. 